\title{
Procedimentos para a prescrição dos recursos de tecnologia assistiva para alunos da educação infantil com paralisia cerebral
}

\author{
Aila Narene Dahwache Criado Rocha* \\ Débora Deliberato** \\ Rita de Cássia Tibério Araújo***
}

\section{Resumo}

A literatura sobre Tecnologia Assistiva enfatiza a necessidade de inserir recursos, serviços e estratégias na educação especial e inclusiva para colaborar com o processo de aprendizagem de alunos com deficiências. $\mathrm{O}$ estudo tem como objetivo descrever procedimentos para a prescrição de recursos de tecnologia assistiva para uso em ambiente escolar. Os participantes são dois alunos com paralisia cerebral e seus professores. Os dados foram coletados através de observação dos alunos em ambientes escolares, tendo como elementos de investigação a capacidade funcional do aluno e as demandas das atividades. O processo de prescrição foi norteado por três etapas, quais sejam: identificar problemas de participação do aluno, refletir sobre possibilidades de auxílio e indicar os recursos adequados para a realização das atividades escolares. O estudo identificou a necessidade de estabelecer procedimentos específicos, um planejamento pedagógico organizado e a participaçáo de profissionais da saúde para o uso da tecnologia assistiva na escola. A descriçáo do processo de prescrição de recursos, apresentada neste estudo, oferece oportunidade de reaplicação do modelo na prática pedagógica, podendo também ser utilizada em programas de capacitação do professor.

Palavras-chave: Tecnologia assistiva; Paralisia cerebral; Escola.

\footnotetext{
* Professora doutora assistente da Universidade Estadual Paulista Júlio de Mesquita Filho, Marília, São Paulo, Brasil.

** Professora doutora da Universidade Estadual Paulista Júlio de Mesquita Filho, Marília, São Paulo, Brasil.

*** Professora doutora assistente da Universidade Estadual Paulista Júlio de Mesquita Filho, Marília, São Paulo, Brasil.
} 


\section{Procedures for the prescription of assistive technology resources for students of education child with cerebral palsy}

\section{Abstract}

The literature about Assistive Technology have emphasized the need to integrate resources, services and strategies for inclusion and special education to foster the learning process and skill development of students with disabilities. This study aimed to describe the procedures for prescribing assistive technology resources for usage in school environment. Two cerebral palsy students participated in the study with their teachers. The data were collected through observation of the participation of these students in school settings. The elements for researching were the functional capacity and the demands of the student's activities. The prescription process was guided by three steps; identifying problems in the student's participation, reflecting on possible aid in the participation, and denoting resources for performing the school activities. The description of the prescription process for the adequate resources to the cerebral palsy student presented in this study provides an opportunity for reapplication of the model in pedagogical practice that can also be used in teacher training programs. The study identified the need to establish specific procedures, an organized pedagogical plan and participation of health professionals as consultants on using assistive technology in school.

Keywords: Assistive technology; Cerebral palsy; School.

\section{Introdução}

A tecnologia assistiva, ou ajudas técnicas, é uma área de conhecimento que vem sendo utilizada para a participação da pessoa com deficiência em diferentes atividades sociais, propiciando novos caminhos e possibilidades para o preenchimento da lacuna que se estabelece entre a capacidade funcional da pessoa e as demandas ambientais. $\mathrm{Na}$ medida em que se situa como instrumento facilitador do desempenho em atividades, a tecnologia assistiva disponibiliza recursos para a participaçáo da pessoa com deficiência, pois permite que ela interaja, relacione-se e possa competir em seu meio com ferramentas mais poderosas (PEREZ, 2003; SORO-CAMATEZ, 2003).

O Comitê de Ajudas Técnicas (CAT) conceituou a Tecnologia Assistiva como:

“Tecnologia Assistiva é uma área do conhecimento, de característica interdisciplinar, que engloba produtos, recursos, metodologias, estratégias, práticas e serviços que objetivam promover a funcionalidade, relacionada à atividade e participação de pessoas com deficiência, incapacidades ou mobilidade reduzida, visando sua autonomia, independência, qualidade de vida e inclusão social. (CAT, 2007)." 
Ao pensar na implementação da tecnologia assistiva na escola, é necessário conhecer o aluno, sua história, suas necessidades e desejos, bem como identificar quais são as necessidades do contexto escolar, incluindo as necessidades educacionais do professor, as relaçôes interpessoais entre os alunos, os desafios curriculares, as tarefas exigidas no âmbito coletivo da sala de aula e as possíveis barreiras encontradas que lhe impedem o acesso aos espaços da escola ou ao conhecimento (ROSSELL, 2003; DELIBERATO, 2009; PELOSI, 2008; BERSH, 2008; ROCHA; DELIBERATO, 2009A, 2009B, SAMESHIMA; DELIBERATO, 2009; ROCHA, 2010; 2013).

A tecnologia assistiva tem sido utilizada no contexto escolar para criar ambientes mais propícios à aprendizagem e, para isto, seus serviços, recursos e estratégias possibilitam aos alunos com deficiência ampliar suas habilidades e desenvolver um sentimento de controle sobre o processo de aprendizagem (DELIBERATO, 2009; ROCHA; DELIBERATO, 2012).

Pelosi (2006) discutiu que o sucesso do processo de inclusão está estreitamente relacionado à possibilidade de reconhecer e aceitar as diferenças. Isso não significa ignorá-las e colocar as crianças com necessidades educacionais especiais em sala de aula regular e esperar que as mesmas aprendam pela proximidade com seus colegas, mas sim, oferecer os recursos necessários para que a criança aprenda. A tecnologia assistiva favorece a aprendizagem e o desenvolvimento da criança com deficiência, pois permite que ela participe com maior eficácia nas atividades de rotina em seu ambiente natural (SORO-CAMATS, 2003; MISTRETT et al., 2005; DELIBERATO; 2009).

A literatura internacional também vem discutindo os recursos e serviços de tecnologia no ambiente escolar. Neste contexto, Judge, Floyds e Jeffs (2008) tiveram como objetivo descrever uma lista de recursos da tecnologia assistiva, para uso de crianças e jovens com deficiências, que podem ser facilmente adquiridos e utilizados por profissionais da educação. Entre os recursos, é possível identificar os de alta tecnologia, como computadores e softwares específicos, como também recursos de baixa tecnologia. Os recursos de baixa tecnologia podem ser confeccionados pelo professor a partir de materiais que fazem parte do cotidiano escolar (BRASIL, 2006).

Outro aspecto importante discutido na área de tecnologia assistiva é a adaptação do ambiente frente à diversidade de habilidades e necessidades da pessoa com deficiência. No ambiente escolar, o uso da TA favorece a otimização de habilidades e constitui um meio de viabilização da ampliação da aprendizagem, pois as crianças têm o desejo natural de explorar os seus ambientes (JUDGE; FLOYD; JEFFS, 2008).

$\mathrm{O}$ processo de implementação da tecnologia assistiva envolve uma sequência de procedimentos. Levando em conta os aspectos operacionais da prescrição, Manzini e Santos (2002) indicaram e descreveram etapas para implementar a prescrição de recursos de tecnologia assistiva no ambiente escolar. A seguir, a Figura 1 representa o percurso estabelecido pelos autores: 


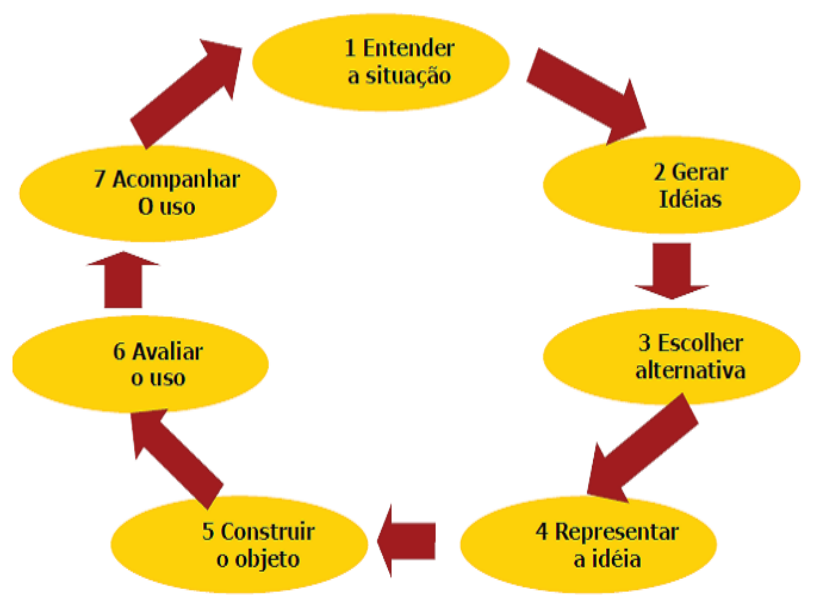

Figura 1: Fluxograma para desenvolvimento de tecnologia assistiva na escola (MANZINI; SANTOS; 2002).

Considerando a importância da sistematização de procedimentos para a prescrição de TA, este estudo teve como objetivo descrever procedimentos de prescrição de recursos de tecnologia assistiva para uso em ambiente escolar.

\section{Material e método}

Este estudo foi aprovado pelo Comitê de Ética de uma Universidade Pública do interior de Sáo Paulo, sob o protocolo n. 2482/2008, e faz parte de um projeto maior, cuja finalidade é descrever o processo de prescrição e confecção de recursos de tecnologia assistiva para crianças com paralisia cerebral no contexto da Educação Infantil.

\section{Participantes}

Participaram desta investigação duas crianças com diagnóstico médico de paralisia cerebral (participante A e participante B) e seus professores.

Os critérios de inclusão dos alunos participantes foram: apresentar diagnóstico de paralisia cerebral e ser aluno da Educação Infantil.

Levando em conta a importância da classificação da paralisia cerebral para a melhor compreensão do seu quadro funcional, foram utilizados dois instrumentos para a caracterização dos participantes. Esses instrumentos classificam a capacidade motora funcional: o GMFCS (Gross Motor Function Measure Classification System), que identifica o nível de função motora grossa (PALISANO et al., 1997) e o MACS (Manual Ability Classification System for Children With Cerebral Palsy), que classifica a habilidade manual de crianças com paralisia cerebral (ELIASSON et al, 2006).

O participante $A$, do gênero masculino, encontrava-se com três anos de idade e apresentava diagnóstico médico de paralisia cerebral caracterizada por quadriparesia 
espástica. Em relação à classificação funcional, no GMFCS a criança foi classificada em nível $\mathrm{V}$ e os resultados do MACS também apontaram para a classificação nível V. Segundo avaliação médica, a criança apresentava baixa visão secundária à lesão no sistema nervoso central, não sendo possível avaliar precisamente a sua visão residual. Em relação à comunicação, iniciou a fala após intervenção por meio de recursos da comunicação alternativa e, no momento da coleta de dados, embora tivesse a possibilidade de utilizar a fala, essa forma de comunicação era restrita aos contextos de suas vivências.

A professora do participante A tinha formação em pedagogia, com experiência de 23 anos no ensino regular, cursara habilitação em deficiência física há 17 anos e atuava em classe especial para deficientes físicos há 14 anos.

O participante $B$, do gênero masculino, encontrava-se com 6 anos de idade, apresentava diagnóstico médico de paralisia cerebral caracterizada por quadro discinético, com distonia generalizada. Referente à sua classificação funcional no GMFCS, a criança foi classificada em nível V e os resultados do MACS indicaram a classificação nível IV. Em relação à comunicação, a criança apresentava discurso ininteligível com vocalizaçóes e emissóes de algumas palavras, caracterizando, assim, um quadro clínico com alteraçóes nas habilidades fonológicas, lexicais e semânticas, segundo diagnóstico fonoaudiológico. $\mathrm{O}$ aluno se comunicava com o auxílio da comunicação alternativa e se expressava através de pranchas de comunicação, gestos e olhar.

A professora do participante B tinha formação em pedagogia e artes, com experiência de 16 anos no ensino regular, não cursara nenhum curso específico para trabalhar com crianças com necessidades especiais. Segundo relato da professora, ela possuía experiência de 5 anos na atuação com alunos que apresentavam deficiência intelectual matriculados em classe regular e, no ano da realização desta pesquisa, era a primeira vez que ela recebia crianças com deficiência física.

\section{Procedimentos de coleta de dados}

$\mathrm{O}$ processo de sistematização de procedimentos relacionados à prescrição de TA ocorreu durante 11 meses, de agosto de 2008 a julho de 2009.

O processo de sistematização da prescrição de TA englobou as três primeiras etapas do fluxograma para desenvolvimento de tecnologia assistiva na escola, proposto por Manzini e Santos (2002), quais sejam: entender a situação, gerar ideias e escolher as alternativas.

A cada etapa corresponderam procedimentos específicos, aplicados num continuum, conforme quadro 1. 


\begin{tabular}{|l|l|}
\hline \multicolumn{1}{|c|}{ Etapas do fluxograma } & \multicolumn{1}{|c|}{$\begin{array}{c}\text { Procedimentos/instrumentos de coleta } \\
\text { de dados }\end{array}$} \\
\hline $\begin{array}{l}\text { 1. Entender a situaçáo: identificar problemas } \\
\text { de participaçáo do aluno. }\end{array}$ & $\begin{array}{l}\text { Entrevista com os professores; } \\
\text { Observação do aluno em sala de aula } \\
\text { registrada por meio de um Protocolo } \\
\text { intitulado "Protocolo de Identificação de } \\
\text { Rotina Escolar", filmagens e anotaçóes em } \\
\text { diário de campo. }\end{array}$ \\
\hline $\begin{array}{l}\text { 2. Gerar ideias: identificar as possibilidades } \\
\text { de auxílio na participação do aluno. }\end{array}$ & $\begin{array}{l}\text { Nesta etapa, foi realizada a triangulação } \\
\text { dos dados coletados na Etapa 1 segundo a } \\
\text { proposta de Trivinos (1992), bem como a } \\
\text { Análise de Conteúdo proposta por Bardin } \\
\text { (2002). } \\
\text { Após estes procedimentos, foi realizada } \\
\text { identificação de elementos norteadores para } \\
\text { pensar em possibilidades de recursos de } \\
\text { tecnologia assistiva na escola. }\end{array}$ \\
\hline $\begin{array}{l}\text { 3. Escolher as alternativas: indicar os } \\
\text { recursos adequados para a realizaçáo das } \\
\text { atividades escolares. }\end{array}$ & $\begin{array}{l}\text { Neste momento, foi proposto critérios a } \\
\text { fim de nortear a prescrição de recursos de } \\
\text { tecnologia assistiva com base nos resultados } \\
\text { anteriores, bem como com o apoio da } \\
\text { literatura da área. } \\
\text { Por fim, foi realizada a prescrição dos } \\
\text { recursos baseada nas alternativas viáveis para } \\
\text { o contexto do aluno. }\end{array}$ \\
\hline
\end{tabular}

Quadro 1: Procedimentos utilizados na sistematizaçấo da prescriçấo de TA.

\section{Resultados e discussão}

Segundo Cook e Hussey (2002), ao pensar no recurso de tecnologia assistiva, é importante conhecer as características individuais da criança, identificar as necessidades especificas das atividades planejadas em diferentes contextos e estabelecer os recursos e serviços da tecnologia assistiva a serem utilizados. A soma destes três aspectos irá favorecer a confecçáo de recursos de tecnologia assistiva para a criança com paralisia cerebral. O recurso e as estratégias adequadas para viabilizar o seu uso, podem proporcionar melhor desempenho durante as atividades, ampliação de sua comunicação, maior autonomia e a aquisição de novas habilidades (PELOSI, 2006; 2008; PERES, 2003; ROSSELL, 2003; SORO-CAMATEZ, 2003; DELIBERATO, 2004, 2009; BERSH, 2008; ROCHA; DELIBERATO, 2009A, 2012; SAMESHIMA; DELIBERATO, 2009). 


\section{Com relação ao procedimento "entender a situação"}

A utilização de parâmetros que levam o profissional a entender o contexto da criança antes da prescrição do recurso pode ser uma estratégia para ajudar na sua escolha e inserção da tecnologia assistiva (JUDGE; FLOYD; JEFFS, 2008).

Para direcionar os serviços de tecnologia assistiva e entender a situação do aluno com paralisia cerebral, foram utilizadas, neste trabalho, as categorias propostas por Rocha (2010):

1) Ambiente: identificação dos locais onde a criança realiza atividades na escola, como por exemplo, a sala de aula, o refeitório, o banheiro, sala de vídeo, pátio, parque, tanque de areia, entre outros locais.

2) Interlocutores mediadores: identificação das pessoas que participaram das diferentes atividades da rotina escolar, ou seja, as pessoas que permanecem na sala de aula e em outros locais da escola, como por exemplo, a professora, auxiliares de sala, merendeira, coordenadora pedagógica, o motorista entre outras.

3) Recursos: são os recursos convencionais oferecidos pela escola e utilizados por todos os alunos, inclusive o aluno participante desta pesquisa, bem como os recursos de tecnologia assistiva presentes na escola, ou seja, os recursos modificados adequados para as especificidades do aluno com deficiência.

4) Estratégias: são os procedimentos de execução utilizados pelos interlocutores mediadores a fim de mediar o uso dos recursos para a realização de uma atividade, ou seja, como o professor e/ou os demais profissionais utilizavam um recurso para conseguir um objetivo estabelecido.

5) Participaçáo do aluno: foi identificado como o aluno realizou açóes motoras, comunicativas, perceptivas e comportamentais durante as atividades realizadas no contexto escolar utilizando os recursos convencionais da escola ou recursos de tecnologia assistiva na escola.

6) Desempenho: foi identificado o desempenho motor (rendimento e a qualidade da açáo motora e do posicionamento do aluno durante atividades), o desempenho perceptivo (o rendimento e a qualidade dos aspectos auditivos, visuais, táteis do aluno durante as atividades) e o desempenho comunicativo (foi considerada a compreensão do aluno nos momentos durante as instruçôes feitas pelos interlocutores mediadores nas diferentes modalidades expressivas e também suas diferentes modalidades de expressôes.

7) Conduta do aluno: foi considerado as reaçôes do aluno frente a um estímulo desencadeado pela sua participação nas atividades. Foram consideradas as reaçóes de alegria, tristeza, birra, choro.

Complementando essas categorias, a literatura também sinaliza que para o uso da TA na escola é necessário conhecer: o aluno, as necessidades do contexto escolar, seus colegas de classe, o planejamento do professor, o conteúdo curricular, 
as demandas no âmbito coletivo da sala de aula e as possíveis barreiras encontradas que impedem o acesso do aluno aos espaços da escola ou ao conhecimento (PELOSI, 2006, 2008; ROSSELL, 2003; DELIBERATO, 2004, 2009; BERSH, 2008; ROCHA; DELIBERATO, 2009A, 2009B; ROCHA, 2010; 2013).

Perante estes aspectos, foram estabelecidos três elementos para serem os norteadores junto com as categorias descritas por Rocha (2010), sendo eles: características do aluno com deficiência, planejamento do professor e desempenho esperado para a sala de aula.

O cruzamento das categorias de Rocha (2010) com os elementos norteadores forneceram subsídios para estabelecer metas com o propósito de gerar ideias de prescrição de recursos de TA (Quadro 2).

\begin{tabular}{|c|c|c|c|}
\hline Categorias & $\begin{array}{l}\text { Característica do aluno } \\
\text { com deficiência }\end{array}$ & $\begin{array}{l}\text { Planejamento do } \\
\text { professor }\end{array}$ & $\begin{array}{l}\text { Desempenho da } \\
\text { classe }\end{array}$ \\
\hline Ambiente & $\begin{array}{l}\text { Favorecer a participação } \\
\text { do aluno com deficiência. }\end{array}$ & $\begin{array}{l}\text { Adequar o ambiente } \\
\text { para a diversidade do } \\
\text { aluno. }\end{array}$ & $\begin{array}{c}\text { Adequar as } \\
\text { demandas das } \\
\text { tarefas para a } \\
\text { participaçáo do } \\
\text { aluno junto aos } \\
\text { demais alunos da } \\
\text { classe. }\end{array}$ \\
\hline $\begin{array}{l}\text { Interlocutores } \\
\text { e mediadores }\end{array}$ & Favorecer a interação. & $\begin{array}{c}\text { Mediar a participação } \\
\text { do aluno com } \\
\text { os diferentes } \\
\text { interlocutores. }\end{array}$ & $\begin{array}{c}\text { Estimular a } \\
\text { iniciativa de } \\
\text { interação dos } \\
\text { alunos da classe. }\end{array}$ \\
\hline Recurso & $\begin{array}{l}\text { Identificar a indicação } \\
\text { de atributos do material: } \\
\text { forma, tamanho, cor, } \\
\text { peso, textura, consistência. }\end{array}$ & $\begin{array}{c}\text { Estabelecer os } \\
\text { objetivos para o uso do } \\
\text { recurso. }\end{array}$ & $\begin{array}{c}\text { Adequar o recurso } \\
\text { à faixa etária dos } \\
\text { alunos da classe. }\end{array}$ \\
\hline Estratégias & $\begin{array}{c}\text { Estabelecer os } \\
\text { procedimentos necessários } \\
\text { para utilizar o recurso na } \\
\text { tarefa. }\end{array}$ & $\begin{array}{c}\text { Estabelecer } \\
\text { procedimentos } \\
\text { para desenvolver o } \\
\text { conteúdo. }\end{array}$ & $\begin{array}{l}\text { Contemplar a } \\
\text { aplicaçáo do } \\
\text { recurso junto aos } \\
\text { alunos da classe. }\end{array}$ \\
\hline Participação & $\begin{array}{c}\text { Identificar as } \\
\text { necessidades motoras, de } \\
\text { comunicação, sensoriais, } \\
\text { perceptuais, cognitivas e } \\
\text { comportamentais. }\end{array}$ & $\begin{array}{l}\text { Criar situaçóes para } \\
\text { favorecer o uso do } \\
\text { recurso. }\end{array}$ & $\begin{array}{l}\text { Inserir o recurso } \\
\text { na rotina de } \\
\text { tarefas de forma } \\
\text { a promover a sua } \\
\text { familiaridade. }\end{array}$ \\
\hline
\end{tabular}


Continuação Quadro 2

\begin{tabular}{|c|c|c|c|}
\hline Desempenho & $\begin{array}{c}\text { O recurso deve favorecer } \\
\text { o desempenho do aluno } \\
\text { levando em conta as } \\
\text { demandas das tarefas. }\end{array}$ & $\begin{array}{c}\text { O uso do recurso } \\
\text { deve contemplar } \\
\text { o conteúdo do } \\
\text { planejamento. }\end{array}$ & $\begin{array}{c}\text { Favorecer o } \\
\text { envolvimento do } \\
\text { grupo de alunos } \\
\text { com o recurso } \\
\text { na estratégia } \\
\text { estabelecida. }\end{array}$ \\
\hline $\begin{array}{c}\text { Conduta do } \\
\text { aluno }\end{array}$ & $\begin{array}{c}\text { Instrumentalizar o aluno } \\
\text { para o uso do recurso. }\end{array}$ & $\begin{array}{c}\text { Criar estratégias } \\
\text { flexíveis para a } \\
\text { motivaçáo do aluno. }\end{array}$ & $\begin{array}{c}\text { Estimular a } \\
\text { aceitaçáo do } \\
\text { recurso pela classe. }\end{array}$ \\
\hline
\end{tabular}

Quadro 2: Metas para gerar ideias de prescrição de recursos de TA.

\section{Com relação ao procedimento "gerar ideias"}

Foi possível identificar que os recursos mais utilizados pelo participante A foram brinquedos como bolas, carrinhos e brinquedos para areia, essas atividades faziam parte do planejamento do professor e contemplavam as necessidades da faixa etária das demais crianças da sala do aluno, como pode ser observado a seguir.

Os dados referentes ao Participante B demonstraram que os recursos mais utilizados pela professora foram aqueles que apoiavam o processo inicial da alfabetização como o caderno, o lápis, o estojo, a lousa, textos digitados, cola, livros, DVDs, lápis de cor e giz de cera, exemplificados a seguir.

Esta diferença entre os recursos utilizados pelas professoras, durante as atividades, além de se justificar pela diferença entre as idades dos participantes, pode estar relacionada a outros dois fatores: o maior comprometimento das crianças da classe especial e também a demanda de conteúdo pedagógico da sala de aula do participante B.

Durante a coleta de dados, foi possível identificar a intenção da professora em oferecer estratégias que pudessem permitir aos participantes a participação nas atividades propostas. A seguir são citados exemplos de atividades:

Participante A

Atividade com música:

[...] ao cantar, a professora passa de criança em criança realizando movimentos com as pernas, braços e pé, conforme a letra da música... durante a música, a professora se dirigiu a cada criança e cantava individualmente com o nome dela [...] a professora ajudou o PA da sala especial a realizar alguns movimentos de braços e pernas.

Tanque de areia:

[..] foi levado uma almofada de courvim para apoio do aluno na cadeira durante atividade no tanque de areia, porém, näo foi totalmente adequado, sendo necessário a professora sentar ao lado e dar apoio com o braço. 
Participante B

Atividade de cabeçalho em sala de aula:

[...] enquanto isto, o Participante B permanece na cadeira e a estagiária com o lápis que pegou do estojo do aluno escreve o cabeçalho que a professora passou na lousa no caderno do aluno que está sobre a carteira. Neste momento, a estagiária náo estabelece nenhum contato com a criança, que direciona o olhar para o lado contrario de onde se encontra o caderno [...].

Atividade de matemática:

A estagiária pega os palitos novamente em sua mão, leva até a mesa de apoio próximo a mão direita da criança e diz:

Estagiária: Tira dois, tira dois para a tia

A criança joga a cabeça para trás e sem olhar leva a mão direita até a mão da estagiária e tira um palito. A estagiaria então diz:

Estagiária: Mais um

$O$ participante $B$ leva novamente a mão direita e retira o palito, a estagiária então espalha os palitos de sorvete na mão e diz:

Estagiária: Quantos ficaram? Conta para tia? Quanto?

A criança emite alguns sons que a estagiária náo compreende e ela diz:

Estagiária: Quantos palitos têm aqui na mãozinha da tia?

A criança emite sons que ela não compreende e ela diz:

Estagiária: $A$ h

Apesar de as professoras desenvolverem estratégias para maior participação da criança nas atividades, os procedimentos não foram suficientes para garantir a acessibilidade dos participantes para o uso dos recursos que estão presentes na escola, ou seja, os recursos que não estão adequados às necessidades do aluno.

A partir dos exemplos apresentados, seria necessário que o professor e os demais profissionais envolvidos nas ações anteriormente descritas estivessem capacitados e dispostos para desenvolver estratégias a fim de otimizar a participação do aluno e assim oferecer ferramentas para ampliar suas habilidades motoras, comunicativas, perceptivas e sociais (PARETTE; BROTHERSON; HUER, 2000; LAHM; SIZEMORE, 2002, PELOSI, 2008; DELIBERATO, 2009; ROCHA; DELIBERATO, 2009A, 2012; SAMESHIMA; DELIBERATO, 2009).

Embora seja necessário reconhecer as necessidades individuais das crianças com deficiência física, a escola tem o compromisso de oferecer recursos e estratégias que viabilizem o seu aprendizado (JUDGE; FLOYD; JEFFS, 2008).

Também foi possível identificar que, apesar de a escola oferecer recursos para o posicionamento do participante A, tais como cadeira de rodas, prancha em "u", "calça da vovó", rolo e cunha de posicionamento e cinto de fixação, esses recursos não se adequavam às medidas antropométricas da criança, fato que também prejudicou a realização das atividades planejadas pela professora, pois os recursos de posicionamento não proporcionavam a adequação postural necessária para a realização das tarefas. 
Quanto ao participante B, apesar de o recurso para posicionamento ser de uso pessoal, observou-se que o mesmo não estava adequado às suas necessidades, dificultando as atividades, principalmente as que necessitavam do uso de membros superiores e atenção direcionada, tendo-se observado a seguinte situação:

\section{No momento em que a professora se aproxima do andador, o Parti- cipante $B$ se desestabiliza, iniciando uma sequência de movimentos involuntários. Através dos movimentos dos pés desloca o andador para trás sem a intençâo de realizar esta ação, desloca todo o corpo para a esquerda e continua uma sequência de movimentos involuntários.}

Estudos destacaram que adequando a postura das crianças com paralisia cerebral, dando-lhes pontos de apoio e estabilidade, é possível atenuar as alteraçóes de tônus muscular, melhorar a mobilidade e diminuir os movimentos involuntários, e, com isso, oferecer condiçóes para que o aluno possa atuar sobre objetos e materiais escolares; consequentemente poderá permanecer com melhor contato e seguimento visual do espaço e, além disso, sua atenção poderá estar direcionada para atividades mais complexas (BEUKELMAN; MIRENDA, 2007; BRACCIALLI; MANZINI; VILARTA, 2005; BRASIL, 2007; BERSH, 2008; BRACCIALLI et al., 2008).

Com relação ao participante $\mathrm{A}$, observaram-se dificuldades no desempenho motor, comunicativo e perceptivo. Embora o aluno manifestasse comportamento indicativo de interesse em realizar as atividades, o ambiente, os recursos e as estratégias não estavam adequados, o que dificultava a sua participação e evidenciava ainda mais suas limitaçóes.

O participante B apresentou prejuízo no desempenho motor e comunicativo, evidenciando-se também prejuízo da sua participação nas atividades planejadas pela professora.

Os dados observados sobre os participantes A e B podem estar relacionados aos resultados descritos na pesquisa de Copley e Ziviani (2004), que identificaram os obstáculos no uso de recursos de tecnologia assistiva no contexto escolar. Entre as principais dificuldades encontradas pelo professor, estavam as avaliaçóes e os processos de planejamento inadequados, dificuldades de gestáo e aquisição de recursos, financiamento insuficiente, limitaçóes do tempo, a falta de uma adequada formaçáo dos profissionais e a falta de uma equipe de apoio.

A criança com deficiência encontra dificuldades na interação com o meio, mas isto não pode ser entendido como um problema restrito ao seu déficit. $\mathrm{O}$ uso de estratégias para adequar o meio será determinante para ampliar a descoberta de habilidades e de possibilidades da criança no contexto escolar (JUDGE; FLOYD; JEFFS, 2008; ROCHA, 2010, 2013).

Manzini (1999) considerou que o elemento central norteador da atuação do professor é o planejamento de atividades a partir de um determinado objetivo, que pode náo ser alcançado dependendo dos recursos utilizados na atividade.

Nas situaçóes observadas, os recursos oferecidos aos participantes do estudo não estavam adequados às suas necessidades, impossibilitando-os de atingir os objetivos das atividades planejadas pelas professoras. 
Os professores devem planejar as atividades atendendo às necessidades de todos os alunos; além de planejar a atividade, o professor deve pensar em recursos e estratégias adequados à criança, permitindo que ela participe em base de igualdade com seus pares (PELOSI, 2008; DELIBERATO, 2009A, 2009B; ROCHA; DELIBERATO, 2009A, 2012).

O brincar é fundamental para a criança, e segundo o Referencial Curricular Nacional para a Educação Infantil, as brincadeiras são estratégias utilizadas na escola para garantir que a aprendizagem possa ocorrer (BRASIL,1998).

Diversos foram os pesquisadores que estudaram o BRINCAR (WINNICOT, 1971; VYGOTSKY, 1994; TAKATORI, 2003; MOYLES, 2006; FERLAND, 2006). Ferland (2006) identificou e agrupou alguns brinquedos utilizados por crianças em idade pré escolar. Com o intuito de relacionar os brinquedos com a faixa etária dessas crianças, a autora propóe a divisão de três grupos: 0 a 18 meses; 18 meses a 3 anos e 3 a 6 anos.

É importante ressaltar que, apesar das dificuldades da criança com deficiência física, ela segue a mesma sequência de desenvolvimento do brincar das crianças típicas, porém, é necessário adequar as relaçôes entre o conteúdo e a forma de brincar, ou seja, é necessária a adequação dos recursos e estratégias para que a criança com paralisia cerebral possa participar dessas atividades (FERLAND, 2006).

Levando em conta que os participantes A e B apresentavam três e seis anos respectivamente, foi utilizado como referência para a seleção dos recursos os brinquedos propostos por Ferland (2006).

\section{Com relação a "escolher as alternativas"}

Após os procedimentos anteriores, seria necessário escolher as alternativas que poderiam contribuir com a participação e aprendizagem significativa do aluno com paralisia cerebral no contexto escolar perante o planejamento do professor e em relação ao desempenho dos demais alunos da sala.

Manzini e Santos (2002) consideraram importante estabelecer as necessidades a serem atendidas, a disponibilidade de recursos materiais e o custo para a confecçáo dos recursos.

Desta forma, neste procedimento foram estabelecidos três critérios que permitiriam uma escolha viável do recurso. Os três critérios foram designados a partir das informaçóes dos procedimentos anteriores e, também, segundo a literatura pertinente a este assunto (COPLEY; ZIVIANI, 2004; ARAUJO; MANZINI, 2001; MANZINI, 2005; JUDGE; FLOYD; JEFFS, 2008; PELOSI, 2008, 2009; ROCHA; DELIBERATO, 2009A, 2012), tais como:

- Fácil acesso a materiais para confecção do recurso adaptado: materiais disponíveis na escola e de fácil disponibilidade para o professor

- Orçamento do material: seriam selecionados materiais de baixo custo, ou seja, recursos de baixa tecnologia. 
- Tempo de adaptação do recurso: tempo disponível para a confecção do recurso adaptado.

Segundo Cook e Hussey (2002), ao pensar no recurso de tecnologia assistiva, é importante conhecer as características individuais da criança, identificar as necessidades específicas das atividades planejadas em diferentes contextos e estabelecer os recursos e serviços da tecnologia assistiva a serem utilizados. A soma destes três aspectos irá nortear a confecção de recursos de tecnologia assistiva para a criança com paralisia cerebral. O recurso e as estratégias adequadas para viabilizar o seu uso podem proporcionar melhor desempenho durante as atividades, ampliação de sua comunicação, maior autonomia e a aquisição de novas habilidades (PELOSI, 2006, 2008; PERES, 2003; ROSSELL, 2003; SORO-CAMATEZ, 2003; DELIBERATO; 2004, 2009; BERSH, 2008; ROCHA; DELIBERATO, 2009A, 2009B, ROCHA; DELIBERATO, 2012).

A utilização de parâmetros que levam o profissional a entender o contexto da criança antes da prescrição do recurso pode ser uma estratégia para ajudar na sua escolha e inserção da tecnologia assistiva (JUDGE; FLOYD; JEFFS, 2008).

Manzini (2005) relatou que após entender a situação do aluno é possível relacionar as características deles com um possível recurso a ser confeccionado. Dessa forma, o comportamento observado dos alunos reúne informaçôes que orientam a prescrição de recursos de tecnologia assistiva, incluindo a sua a confecção.

Levando em conta as situaçóes interativas dos participantes A e B, foi possível definir que, para a construção de recursos de tecnologia assistiva, seriam adaptados brinquedos para atividades similares àquelas que estavam no planejamento do professor, ou seja, já eram conhecidas pela criança no ambiente escolar.

A partir desse raciocínio, foram prescritos os seguintes recursos para o participante A: carrinhos, bolas, instrumentos musicais; para o participante B: comunicador em forma de relógio, acionador, jogo com letras e jogo de matemática.

Também surgiu a preocupação em relação ao posicionamento, sendo observado que os dois participantes nâo conseguiam manter uma postura adequada para realizar as atividades propostas pela professora.

A adequação postural é capaz de facilitar os movimentos, possibilitando o uso mais adequado das mãos, a melhora e aumento do campo visual e coordenação visomotora, a melhora da atenção e concentração, além da melhora das condiçốes para o aprendizado (BRACCIALLI; MANZINI \& VILARTA, 2005; BEUKELMAN; MIRENDA, 2007; BRASIL, 2007; BERSH, 2008; BRACCIALLI et al., 2008).

Em relação ao participante $\mathrm{A}$, optou-se por adaptar os mobiliários e recursos já disponíveis na escola. Embora os mobiliários e recursos não fossem prescritos especificamente para a criança em estudo, conforme já destacado anteriormente, foi possível adaptá-los às suas necessidades, utilizando a própria regulagem do equipamento, além de cintos, mesas de apoio, almofadas e rolos disponíveis na escola (BEUKELMAN; MIRENDA, 2007; BRACCIALLI; MANZINI; VILARTA, 2005; BRASIL, 2007; BERSH, 2008; BRACCIALLI et al., 2008). 
Em relação ao posicionamento do membro superior do participante A, devido ao seu padrão flexor, foi identificada a necessidade de órteses de posicionamento para punho, mãos e dedos (direita e esquerda) e órteses para a abdução do polegar (direita e esquerda).

Quanto ao participante B, optou-se por prescrever para a escola a necessidade de uma cadeira de rodas adaptada às necessidades posturais do aluno, a fim de promover alinhamento postural, estabilidade e conforto. A literatura descreve que estes elementos podem contribuir para a participação do aluno com paralisia cerebral nas atividades (BERSH, 2010; BEUKELMAN; MIRENDA, 2007; BRACCIALLI et al., 2008).

$\mathrm{O}$ alinhamento e a estabilidade postural seriam fundamentais para que o participante $\mathrm{B}$ pudesse explorar o meio, mantendo a atençáo por tempo prolongado e agindo de forma ativa.

Ao escolher as alternativas para a adaptação dos brinquedos, foram priorizados os recursos de baixa tecnologia, pois os professores teriam maior acesso aos materiais necessários para estas adaptaçóes e o custo desses recursos seria relativamente baixo quando comparado aos recursos de alta tecnologia (SORO-CAMATS, 2003; BRACCIALLI, 2007).

Os recursos de baixa tecnologia são os equipamentos com pouca sofisticação e confeccionados com materiais de baixo custo disponíveis no dia-a-dia. Estes equipamentos são produzidos de maneira mais artesanal e individualizada. Este tipo de recurso pode ser confeccionado pelos próprios familiares do usuário ou por profissionais envolvidos. No Brasil, existe uma predominância na indicação e confecção de equipamentos de baixa tecnologia (PELOSI, 2006; BRACCIALLI, 2007).

O uso de recursos de baixa tecnologia na etapa da Educação Infantil é capaz de atender a demandas específicas nas atividades planejadas pelo professor do aluno com paralisia cerebral, o que é fundamental para garantir a acessibilidade para o seu processo de aprendizagem.

Como exemplo, Galvão Filho (2009) enumerou recursos de tecnologia assistiva de baixo custo que poderiam estar presentes em salas de aula: suportes para visualização de textos ou livros; fixação do papel ou caderno na mesa com fitas adesivas; engrossadores de lápis ou caneta confeccionados com esponjas enroladas e amarradas ou com tubos de PVC; substituição da mesa por pranchas de madeira ou de acrílico fixadas na cadeira de rodas; órteses; entre outros.

Os recursos de baixa tecnologia podem ser construídos pelos próprios professores com materiais da própria escola (BRASIL, 2006). Os profissionais que estão capacitados a confeccionar os recursos de tecnologia assistiva de baixo custo podem adequar o recurso às necessidades do aluno, para que ele tenha a oportunidade de melhorar o seu desempenho e, consequentemente, sua participação em sala de aula.

Outro fator fundamental para o uso do recurso de tecnologia assistiva no contexto escolar é que o equipamento deve estar disponível para atender às demandas das atividades conforme o planejamento do professor. 


\section{Considerações finais}

A sistematização de procedimentos norteadores da prescrição de recursos de TA vem ao encontro das necessidades operacionais dos profissionais que atuam com alunos que apresentam necessidades educacionais especiais.

Este estudo, ao descrever o processo de prescrição de recursos de TA, oferece subsídios para a ampliação da aplicação do conhecimento para outras áreas de deficiência e outras situaçóes educacionais.

Destaca-se, também, a importância do estudo para a implementação de conteúdo curricular visando à capacitação do professor, no que tange ao referencial teórico e prático da aplicação de uma abordagem direcionada para o uso da TA.

\section{Referências}

ARAÚJO, R. C. T.; MANZINI, E. J. Recursos de ensino na escolarizaçăo do aluno deficiente físico. In: MANZINI, E. J. (Org.). Linguagem, cogniçáo e ensino do aluno com deficiência. Unesp, 2001, p. 1-11.

BARDIN, L. Análise de conteúdo. Lisboa: Ediçốes 70, 2004.

BEUKELMAN, D. R.; MIRENDA, P. Augmentative \& alternative communication: supporting children \& adults with complex communication needs. Baltimore: Paul H. Brookes Publishing, 2007.

BERSCH, Rita. et al. Fatores humanos em tecnologia assistiva: uma análise de fatores críticos nos sistemas de prestaçấo de serviços. Revista Plurais, Salvador: UNEB, v. 1, n. 1, p, 34-41, 2010.

BRACCIALLI, L. M. P. Tecnologia assistiva: perspectiva de qualidade de vida para pessoas com deficiência. In: VILARTA, R.; et al. (Orgs.). Qualidade de vida e novas tecnologias. Campinas: IPES, 2007, p. 105-114.

BRACCIALLI, L. M. P.; MANZINI, E. J.; VILARTA, R. Influência do mobiliário adaptado na variaçăo angular da curvatura lombar de indivíduos com paralisia cerebral espástica. Fisioterapia Brasil, v. 6, n. 2, p. $1142-1146,2005$

BRACCIALLI, L. M. P. et al. Influência do assento da cadeira adaptada na execuçáo de uma tarefa de manuseio. Revista Brasileira de Educaçáo Especial, Marília: ABPEE, v. 1, n. 14, p. 141-154, 2008. Quadrimestral.

BRASIL. Referencial curricular nacional para a educaçáo infantil. Brasília: Ministério da Educação MEC/ SEF, 1998.

Sala de Recursos Multifuncionais: espaços para o Atendimento Educacional Especializado. Brasília: MEC/SEESP, 2006.

Atendimento Educacional Especializado - Deficiência Física. Brasília: MEC/SEESP/SEED, 2007.

CAT - Comitê de Ajudas Técnicas. Ata da Reuniáo V, de agosto de 2007 do Comitê de Ajudas Técnicas. Secretaria Especial dos Direitos Humanos da Presidência da República (CORDE/SEDH/PR), 2007. Disponível em: <http:// http://www.mj.gov.br/corde/comite.asp>. Acesso em: 16 set. 2009.

COOK, A. M.; HUSSEY, S. M. Assistive technologies: principles and practice. 2. ed. New York: Mosby, 2002.

COPLEY, J.; ZIVIANI, J. Barriers to the use of assistive technology for children with multiple disabilities. Occupational Therapy International. United States, v. 11, n. 4, p. 229-243, 2004.

DELIBERATO, D. Aspectos teóricos e metodológicos na comunicação alternativa: contribuiçóes para a Educação Especial. Revista Brasileira de Educação Especial, v. 10, p. 387-388, 2004

Comunicação Alternativa na escola: habilidades comunicativas e o ensino da leitura e escrita. In: DELIBERATO, D.; GONÇALVES, M. J.; MACEDO, E. C. (Orgs.). Comunicaçáo alternativa: teoria, prática, tecnologias e pesquisa.1. ed. São Paulo: MEMNON Ediçóes Científicas, 2009a, v. 1, p. 235-243.

. Uso de expressōes orais durante a implementaçâo do recurso de comunicação suplementar e alternativa. Revista Brasileira de Educaçáo Especial, v. 15, p. 369-388, 2009 b.

ELIASSON, A. C. et al. The Manual Ability Classification System (MACS) for children with cerebral palsy: scale development and evidence of validity and reliability. Dev Med Child Neurol. v. 48, n. 7, 2006, p. 549-54. 
FERLAND, F. O Modelo Lúdico: o Brincar, a Criança com Deficiência Física e a Terapia Ocupacional. São Paulo: Editora Roca, 2006.

GALVÃO FILHO, T. A. Tecnologia assistiva para uma escola inclusiva: apropriaçấo, demandas e perspectivas. 2009, 346 f. Tese (Doutorado em educação) - Faculdade de Educação, Universidade Federal da Bahia, 2009.

JUDGE, S.; FLOYD, K.; JEFFS, T. Using an Assistive Technology Toolkit to Promote Inclusion. Early Childhood Education Journal, United States, v. 36, p. 121-126, 2008.

LAHM, E. A.; SIZEMORE, L. Factors that influence assistive technology decision-making. Journal of Special Education Technology, United States, v. 17, n. 1, p. 15-26, 2002.

MANZINI, E. J. Recursos pedagógicos para o ensino de alunos com paralisia cerebral. Mensagem da APAE, v. 36, n. 84 , p. $17-21,1999$.

Tecnologia assistiva para educação: recursos pedagógicos adaptados. In: Ensaios pedagógicos: construindo escolas inclusivas. Brasília: SEESP/MEC, p. 82-86, 2005.

MANZINI, E. J. ; SANTOS, M. C. F. Portal de ajudas técnicas para a educaçáo: equipamento e material pedagógico para educação, capacitação e recreação da pessoa com deficiência - recursos pedagógicos adaptados. 1. ed. Brasília: MEC, v. 1, 2002, 56 p.

MISTRETT, S. G.; LANE, S. J.; RUFFINO, A. G. Growing and learning through technology: Birth to five. In: EDYBURN, D.; HIGGINS, K; BOONE, R. (Orgs.). Handbook of special education technology research and practice. Whitefish Bay, WI: Knowledge by Design. p. 273-307, 2005.

MOYLES, J. R. A exelência do brincar. Porto Alegre: Ed Artmed, 2006.

PALISANO, R., et al. Development and reliability of a system to classify gross motor function in children with cerebral palsy. Dev Med Child Neurol, v. 39, n. 4, p. 214-23, 1997.

PARETTE, H. P.; BROTHERSON, M. J.; HUER, M. B. Giving families a voice in augmentative and alternative communication decision making. Education and Training in Mental Retardation and Developmental Disabilities, v. 35, n. 2, p. 177-190, 2000.

PELOSI, M. B. Por uma escola que ensine e não apenas acolha: recursos e estratégias para a inclusão escolar. In: MANZINI, E. J. Inclusáo e Acessibilidade, Marília: ABPEE, 2006, p. 121-132.

Inclusáo e Tecnologia Assistiva. 2008. Volumes I e II, 303f. Tese (Doutorado em Educaçáo) - Programa de Pós-graduação em Educação da Faculdade de Educação, Universidade do Estado do Rio de Janeiro, Rio de Janeiro, 2008.

Tecnologias em comunicação alternativa sob o enfoque da terapia ocupacional. In: DELIBERATO, D.; GONÇALVES, M. J.; MACEDO; E. C. (Org.). Comunicação alternativa: teoria, prática, tecnologias e pesquisa. São Paulo: Memnon Ediçôes Científicas, 2009. p. 163-173.

PERES, R. C. N. C. O lúdico no desenvolvimento da criança com paralisia cerebral espástica. 2003, $242 \mathrm{f}$. Tese (Doutorado em Educação) - Faculdade de Educação, Universidade de São Paulo, São Paulo, 2003.

ROCHA, A. N. D. C. Processo de prescrição e confecçáo de recursos de tecnologia assistiva para Educaçáo Infantil. 2010. 199f. Dissertação (Mestrado) - Faculdade de Filosofia e Ciências, Universidade Estadual Paulista, Marília, 2010.

Recursos e estratégias da tecnologia assistiva a partir do ensino colaborativo entre os profissionais da saúde e da educaçáo. 2013. 210f. Tese (Doutorado) - Faculdade de Filosofia e Ciências, Universidade Estadual Paulista, Marília, 2013.

O uso de recursos de tecnologia assistiva como instrumento facilitador de atividades pedagógicas de crianças com encefalopatia crônica não progressiva In: Congresso brasileiro de comunicaçáo alternativa ISAAC/BRASIL, 3., 2009, São Paulo. Anais - III Congresso Brasileiro de Comunicação Alternativa - ISSAC/ Brasil. Marília: ABPEE, 2009a, p. 1-9.

A tecnologia assistiva como instrumento facilitador da inclusão escolar de alunos com deficiência física. In: Congresso brasileiro multidisciplinar de educaçáo especial, 5., 2009, Londrina. Anais V Congresso Brasileiro Multidisciplinar de Educação Especial. Londrina: ABPEE, 2009b. v. 1, p. 1150 -1158.

Atuação do terapeuta ocupacional no contexto escolar: o uso da tecnologia assistiva para o aluno com paralisia cerebral na educação infantil. Revista de Terapia Ocupacional da Universidade de Sáo Paulo, Brasil, v. 23, n. 3, p. 263-273, dez. 2012. ISSN 2238-6149. 
ROCHA, A. N. D. C. Processo de prescriçáo e confecçáo de recursos de tecnologia assistiva para Educaçáo Infantil. 2010. 199f. Dissertação (Mestrado) - Faculdade de Filosofia e Ciências, Universidade Estadual Paulista, Marília, 2010.

Recursos e estratégias da tecnologia assistiva a partir do ensino colaborativo entre os profissionais da saúde e da educaçáo. 2013. 210f. Tese (Doutorado) - Faculdade de Filosofia e Ciências, Universidade Estadual Paulista, Marília, 2013.

ROSSELL, C. Comunicação e acesso ao currículo escolar para alunos que utilizam sistemas aumnetativos. In: ALMIRALL, C. B.; SORO-CAMATS, E.; BULTÓ, C. R. (Org.). Sistemas de sinais e ajudas técnicas para a comunicaçáo alternativa e a escrita: princípios teóricos e aplicaçóes. São Paulo: Livraria Santos Editora, 2003. p. $121-133$

SAMESHIMA, F. S.; DELIBERATO, D. Habilidades expressivas de um grupo de alunos com paralisia cerebral na atividade de jogo. Revista da Sociedade Brasileira de Fonoaudiologia, v.14, p. 219-224, 2009.

SORO-CAMATS, E. Uso de ajudas técnicas para a comunicação, o jogo, a mobilidade e o controle do meio: uma abordagem habilitadora. In: ALMIRALL, C. B.; SORO-CAMATS, E.; BULTÓ, C. R. (Orgs.). Sistemas de sinais e ajudas técnicas para a comunicaçáo alternativa e a escrita: princípios teóricos e aplicações. São Paulo: Livraria Santos Editora, 2003, p. 23-41.

TAKATORI, M. O brincar no cotidiano da criança com disfunçáo física: reflexões sobre a clínica da Terapia Ocupacional. São Paulo: Editora Atheneu, 2003.

TRIVIÑOS, A. N. S. Introduçáo à pesquisa em ciências sociais: a pesquisa qualitativa em educação. 3 ed. São Paulo: Atlas, 1992.

VYGOTSKY, L. S. The problem of the environment. In: VEER, R.; VALSINER, J. (Orgs.). The Vygotsky reader. Oxford: Blackwell, 1994, p. 338-354.

WINNICOTT, D. W. O brincar e a realidade. Rio de Janeiro: Imago, 1971. 118p.

\section{Correspondência}

Aila Narene Dahwache Criado Rocha - Universidade Estadual Paulista Júlio de Mesquita Filho, Faculdade de Filosofia e Ciências - Campus de Marília. R. Hygino Muzzi Filho, 737, Cascata. CEP: 17515-330 - Marília, São Paulo, Brasil.

E-mail: aila@marilia.unesp.br - delibera@marilia.unesp.br - ritac@marilia.unesp.br

Recebido em 17 de junho de 2014

Aprovado em 14 de maio de 2015 